\title{
Uniform requirements for manuscripts submitted to biomedical journals
}

\author{
INTERNATIONAL COMMITTEE OF MEDICAL JOURNAL EDITORS
}

In the 12 years since it was first published the "Uniform requirements for manuscripts submitted to biomedical journals" (the Vancouver style), developed by the International Committee of Medical Journal Editors, has been widely accepted by both authors and editors; over 400 journals have stated that they will consider manuscripts that conform to its requirements. This is the fourth edition of the "Uniform requirements".

I

NJANUARY 1978 A GROUP OF EDITORS FROM SOME MAJOR biomedical journals published in English met in Vancouver and decided on uniform technical requirements for manuscripts to be submitted to their journals. These requirements, including formats for bibliographic references developed for the Vancouver group by the United States National Library of Medicine, were published in three of the journals early in 1979. The Vancouver group evolved into the International Committee of Medical Journal Editors. Over the years the group has revised the requirements slightly; this is the fourth edition.

Over 400 journals have agreed to receive manuscripts prepared in accordance with the requirements. It is important to emphasize what these requirements imply and what they do not.

First, the requirements are instructions to authors on how to prepare manuscripts, not to editors on publication style. (But many journals have drawn on these requirements for elements of their publication styles.)
Second, if authors prepare their manuscripts in the style specified in these requirements, editors of the participating journals will not return manuscripts for changes in these details of style. Even so, manuscripts may be altered by journals to conform with details of their own publication styles.

Third, authors sending manuscripts to a participating journal should not try to prepare them in accordance with the publication style of that journal but should follow the "Uniform requirements for manuscripts submitted to biomedical journals."

Nevertheless, authors must also follow the instructions to authors in the journal as to what topics are suitable for that journal and the types of papers that may be submitted - for example, original articles, reviews and case reports. In addition, the journal's instructions are likely to contain other requirements unique to that journal, such as number of copies of manuscripts, acceptable languages, length of articles and approved abbreviations.

Participating journals are expected to state in their instructions to authors that their requirements are in accordance with the "Uniform requirements for manuscripts submitted to biomedical journals" and to cite a published version.

This document will be revised at intervals. Inquiries and comments from Central and North America about these requirements should be sent to Editor, New England Journal of Medicine, 10 Shattuck Street, Boston, MA 02115, USA; those from other regions should be sent to Editor, British Medical

Committee members: Marcia Angell (New England Journal of Medicine), Linda Hawes Clever (Western Journal of Medicine), Lois Ann Colaianni (Index Medicus), Suzanne and Robert Fletcher (Annals of Internal Medicine), Robin Fox (Lancet), Stephen P Lock (British Medical Journal), George D Lundberg (Journal of the American Medical Association), Magne Nylenna (Tidsskrift für den Norske Laegeforening), Amold S Relman (New England Journal of Medicine), Povl Riis (Danish Medical Bulletin and Journal of the Danish Medical Association), Richard G Robinson (New Zealand Medical Journal), Bruce P Squires (Canadian Medical Association Journal) and Laurel Thomas (Medical Journal of Australia).

This document has also been published in the March 15, 1991 issue of the Canadian Medical Association Journal, the February 7, 1991 issue of the New England Journal of Medicine and the February 9, 1991 issue of the British Medical Journal. It is not covered by copyright and may be copied or reprinted without permission. 
Journal, British Medical Association, Tavistock Square, London WC1H 9JR, United Kingdom. Note that these two journals provide secretariat services for the International Committee of Medical Journal Editors; they do not handle manuscripts intended for other journals. Papers intended for other journals should be sent directly to the offices of those journals.

\section{SUMMARY OF REQUIREMENTS}

Type the manuscript double-spaced, including title page, abstract, text, acknowledgements, references, tables and legends for illustrations.

Each manuscript component should begin on a new page, in the following sequence: title page, abstract and key words, text, acknowledgements, references, tables (each table, complete with title and footnotes, on a separate page), and legends for illustrations.

Illustrations must be good quality, unmounted glossy prints usually $127 \times 173 \mathrm{~mm}(5 \times 7 \mathrm{in})$ but no larger than $203 \times 254$ $\mathrm{mm}(8 \times 10 \mathrm{in})$.

Submit the required number of copies of manuscript and illustrations (see journal's instructions) in a heavy-paper envelope. The submitted manuscript should be accompanied by a covering letter, as described under "Submission of a manuscript," and by permissions to reproduce previously published material or to use illustrations that may identify human subjects.

Follow the journal's instructions for transfer of copyright. Author should keep copies of everything submitted.

\section{PRIOR AND DUPLICATE PUBLICATION}

Most journals do not wish to consider for publication a paper on work that has already been reported in a published paper or is described in a paper submitted or accepted for publication elsewhere. This policy does not usually preclude consideration of a paper that has been rejected by another journal or of a complete report that follows publication of a preliminary report, usually in the form of an abstract. Nor does it prevent consideration of a paper that has been presented at a scientific meeting if not published in full in a proceedings or similar publication. Press reports of the meeting will not usually be considered as breaches of this rule, but such reports should not be amplified by additional data or copies of tables and illustrations. When submitting a paper an author should always make a full statement to the editor about all submissions and previous reports that might be regarded as prior or duplicate publication of the same or very similar work. Copies of such material should be included with the submitted paper to help the editor decide how to deal with the matter.

Multiple publication - that is, the publication more than once of the same study, irrespective of whether the wording is the same - is rarely justified. Secondary publication in another language is one possible justification, provided the following conditions are met.

- The editors of both journals concerned are fully informed; the editor concerned with secondary publication should have a photocopy, reprint or manuscript of the primary version.

- The priority of the primary publication is respected by a publication interval of at least two weeks.

- The paper for secondary publication is written for a different group of readers and is not simply a translated version of the primary paper; an abbreviated version will often be sufficient.

- The secondary version reflects faithfully the data and interpretations of the primary version.

- A footnote on the title page of the secondary version informs readers, peers and documenting agencies that the paper was edited and is being published for a national audience in parallel with a primary version based on the same data and interpretations. A suitable footnote might read as follows: "This article is based on a study first reported in the [title of journal, with full reference]."

Multiple publication other than as defined above is not acceptable to editors. If authors violate this rule they may expect appropriate editorial action to be taken.

Preliminary release, usually to public media, of scientific information described in a paper that has been accepted but not yet published is a violation of the policies of many journals. In a few cases, and only by arrangement with the editor, preliminary release of data may be acceptable - for example, to warn the public of health hazards.

\section{PREPARATION OF A MANUSCRIPT}

Type the manuscript on white bond paper $216 \times 279 \mathrm{~mm}$ $(8 / 2 \times 11$ in $)$ or ISO A4 $(212 \times 297 \mathrm{~mm})$, with margins of at least $25 \mathrm{~mm}$ ( $1 \mathrm{in})$. Type only on one side of the paper. Use double spacing throughout, including title page, abstract, text, acknowledgements, references, tables, and legends for illustrations. Begin each of the following sections on separate pages: title page, abstract and key words, text, acknowledgements, references, individual tables, and legends. Number the pages consecutively, beginning with the title page. Type the page number in the upper or lower right-hand corner of each page.

\section{Title page}

The title page should carry the following: (a) the title of the article, which should be concise but informative; (b) the preferred given name, initials and last name of each author, with the highest academic degree(s) and the institutional affiliation; (c) the name of the department(s) and institution(s) to which the work should be attributed; (d) disclaimers, if any; (e) the name and address of the author responsible for correspondence about the manuscript; (f) the name and address of the author to whom requests for reprints should be addressed or a statement that reprints will not be available from the authors; $(\mathrm{g})$ the source(s) of support in the form of grants, equipment, drugs or all of these; and (h) a short running head or foot line (no longer than 40 characters, counting letters and spaces), placed at the foot of the title page and identified. 


\section{Authorship}

All persons designated as authors should qualify for authorship. The order of authorship should be a joint decision of the co-authors. Each author should have participated sufficiently in the work to take public responsibility for the content.

Authorship credit should be based only on substantial contributions to (a) either conception and design or else analysis and interpretation of data and to (b) drafting the article or revising it critically for important intellectual content and on (c) final approval of the version to be published. All three conditions must be met. Participation solely in the acquisition of funding or the collection of data does not justify authorship. General supervision of the research group is also not sufficient for authorship.

Any part of an article critical to its main conclusions must be the responsibility of at least one author.

A paper with corporate (collective) authorship must specify the key persons responsible for the article; others contributing to the work should be recognized separately (see "Acknowledgements").

Editors may require authors to justify the assignment of authorship.

\section{Abstract and key words}

The second page should carry an abstract (of no more than 150 words for unstructured abstracts or 250 words for structured abstracts). The abstract should state the purposes of the study or investigation, basic procedures (selection of study subjets or laboratory animals; observational and analytic methods), main findings (specific data and their statistical significance, if possible) and the principal conclusions. Emphasize new and important aspects of the study or observations.

Below the abstract provide, and identify as such, three to 10 key words or short phrases that will assist indexers in cross-indexing the article and that may be published with the abstract. Use terms from the medical subject headings (MeSH) list of Index Medicus; if suitable MeSH terms are not yet available for recently introduced terms, present terms may be used.

\section{Text}

The text of observational and experimental articles is usually - but not necessarily - divided into sections with the headings Introduction, Methods, Results and Discussion. Long articles may need subheadings within some sections, especially Results and Discussion, to clarify their content. Other types of articles, such as case reports, reviews and editorials, are likely to need other formats. Authors should consult individual journals for further guidance.

\section{Introduction}

State the purpose of the article. Summarize the rationale for the study or observation. Give only strictly pertinent references, and do not review the subject extensively. Do not include data or conclusions from the work being reported.

\section{Methods}

Describe clearly your selection of the observational or experimental subjects (patients or laboratory animals, including controls). Identify the methods, apparatus (manufacturer's name and address in parenthesis) and procedures in sufficient detail to allow other workers to reproduce the results. Give references to established methods, including statistical (see below); provide references and brief descriptions for methods that have been published but are not well known; describe new or substantially modified methods, give reasons for using them and evaluate their limitations. Identify precisely all drugs and chemicals used, including generic name(s), dosage(s) and route(s) of administration.

\section{Ethics}

When reporting experiments on human subjects indicate whether the procedures followed were in accordance with the ethical standards of the responsible committee on human experimentation (institutional or regional) or with the Helsinki Declaration of 1975, as revised in 1983. Do not use patients' names, initials or hospital numbers, especially in any illustrative material. When reporting experiments on animals indicate whether the institution's or the National Research Council's guide for, or any national law on, the care and use of laboratory animals was followed.

\section{Statistics}

Describe statistical methods in enough detail to enable a knowledgeable reader with access to the original data to verify the reported results. When possible quantify findings and present them with appropriate indicators of measurement error or uncertainty (such as confidence intervals). Avoid sole reliance on statistical hypothesis testing, such as the use of $\mathrm{P}$ values, which fails to convey important quantitative information. Discuss eligibility of experimental subjects. Give details about randomization. Describe the methods for and success of any blinding of observations. Report treatment complications. Give numbers of observations. Report losses to observation (such as dropouts from a clinical trial). When possible, references for study design and statistical methods should be to standard works (with page numbers stated) rather than to the papers in which the designs or methods were originally reported. Specify any general-use computer programs employed.

Put general descriptions of methods in the Methods section. When data are summarized in the Results section specify the statistical methods used to analyze them. Restrict tables and illustrations to those needed to explain the argument of the paper and to assess its support. Use graphs as an alternative to tables with many entries; do not duplicate data in graphs and tables. Avoid nontechnical uses of technical terms in statistics, such as "random" (which implies a randomizing device), "normal," "significant," "correlation" and "sample." Define statistical terms, abbreviations and most symbols.

\section{Results}

Present your results in logical sequence in the text, tables 
and illustrations. Do not repeat in the text all the data in the tables or illustrations: emphasize or summarize only important observations.

\section{Discussion}

Emphasize the new and important aspects of the study and the conclusions that follow from them. Do not repeat in detail data or other material given in the Introduction or the Results section. Include in the Discussion section the implications of the findings and their limitations, including implications for future research. Relate the observations to those of other relevant studies. Link the conclusions with the goals of the study but avoid unqualified statements and conclusions not completely supported by your data. Avoid claiming priority and alluding to work that has not been completed. State new hypotheses when they are warranted, but clearly label them as such. Recommendations, when appropriate, may be included.

\section{Acknowledgements}

At an appropriate place in the article (title-page footnote or appendix to the text; see the journal's requirements) one or more statements should specify the following: (a) contributions that need acknowledging but do not justify authorship, such as general support by a department chairman; (b) acknowledgements of technical help; (c) acknowledgements of financial and material support, specifying the nature of the support; and (d) financial relationships that may pose a conflict of interest.

Persons who have contributed intellectually to the paper but whos contributions do not justify authorship may be named and their function or contribution described - for example, "scientific advice," "critical review of study proposal," "data collection" or "participation in clinical trial." Such persons must have given their permission to be named. Authors are responsible for obtaining written permission from persons acknowledged by name, because readers may infer their endorsement of the data and conclusions.

Technical help should be acknowledged in a paragraph separate from those acknowledging other contributions.

\section{References}

Number references consecutively in the order in which they are mentioned in the text. Identify references in text, tables and legends for illustrations by arabic numerals in parenthesis. References cited only in tables or in legends should be numbered in accordance with a sequence established by the first identification in the text of the particular table or illustration.

Use the style of the examples that follow, which are based, with slight modifications, on the formats used by the United States National Library of Medicine in Index Medicus. The titles of journals should be abbreviated according to the style used in Index Medicus. Consult List of Journals Indexed in Index Medicus, published annually as a separate publication by the library and as a list in the January issue of Index Medicus.

Try to avoid using abstracts as references; unpublished observations and personal communications may not be used as references, although references to written, not oral, communications may be inserted (in parenthesis) in the text. Include among the references papers accepted but not yet published; designate the journal and add "in press" in parenthesis. Information from manuscripts submitted but not yet accepted should be cited in the text as "unpublished observations" (in parenthesis).

The references must be verified by the author(s) against the original documents.

Examples of correct forms of references follow.

Articles in journals

- Standard journal article (List all authors, but if the number exceeds six list six followed by "et al".)

You CH, Lee KY, Chey RY, Menguy R.

Electrogastrographic study of patients with unexplained nauseous bloating and vomiting. Gastroenterology 1980 Aug:79(2):311-4.

As an option, if a journal carries continuous pagination throughout a volume the month and issue number may be omitted.

You CH, Lee KY, Chey RY, Menguy R.

Electrogastrographic study of patients with unexplained nausea, bloating and vomiting, Gastroenterology 1980:79:311-4.

Goate AM, Haynes AR, Owen MJ, Farrell M, James LA. Lai LY, et al. Predisposing locus for Alzheimer's disease on chromosome 21. Lancet 1989:1:352-5.

- Organization as author The Royal Marsden Hospital Bone-Marrow Transplantation Team. Failure of syngeneic bone-marrow graft without preconditioning in post-hepatitis marrow aplasia. Lancet 1977:2:742-4.

- No author given Coffee drinking and cancer of the pancreas (editorial). BMJ 1981:283:628

- Article in a foreign language Massone L, Borghi S, Pestarino A. Piccini R, Gambini C. Localisations primaires purpuriques de la dermatite herpetiforme. Ann Dermatol Venereol 1987; 1 14:1545-7.

- Volume with supplement Magni F. Rossoni G. Berti F. BN-52021 protects guinea pig from heart anaphylaxis. Pharmacol Res Commun 1988:20 Suppl 5:75-8.

- Issue with supplement Gardos G, Cole JO. Haskell D, Marby D. Paine SS, Moore $P$. The natural history of tardive dyskinesia. J Clin Psychopharmacol 1988:8(4 Suppl):31S-37S.

- Volume with part Hanly C. Metaphysics and innateness: a psychoanalytic perspective. Int J Psychoanal 1988:69(P+ 3):389-99.

- Issue with part Edwards L, Meyskens F, Levinc N. Effect of oral isotretinoin on dysplastic nevi. J Am Acad Dermatol 1989:20(2 P+ 1):257-60.

- Issue with no volume Baumeister AA. Origins and control of stereotyped movements. Monogr Am Assoc Ment Defic 1978:(3):353-84.

- No issue or volume Danoek K. Skiing in and through the history of medicine. Nord Medicinhist Arsb 1982:86-100. 
- Pagination in roman rumerals

Ronne Y. Ansvarsfall. Blodtransfusion till fel patient. Vardfacket 1989:13:XXVI-XXVII.

- Type of article indicated as needed Spargo PM. Manners JM. DDAVP and open heart surgery (letter). Anaesthesia 1989:44:363-4.

Fuhrman SA, Joiner KA. Binding of the third component of complement C 3 by Toxoplasma gondii (abstract). Clin Res 1987:35:475A.

- Article containing retraction

Shishido A. Retraction notice: Effect of platinum compounds on murine lymphocyte mitogenesis (Retraction of Alsabti EA. Ghalib ON, Salem MH. In: Jpn J Med Sci Biol 1979:32:53-65). Jpn J Med Sci Biol 1980:33:235-7.

- Article retracted Alsabti EA, Ghalib ON, Salem MH. Effect of platinum compounds on murine lymphocyte mitogenesis (Retracted by Shishido A. In: Jpn J Med Sci Biol 1980;33:235-7). Jpn J Med Sci Biol 1979:32:53-65.

- Article containing comment Piccoll A. Bossatti A. Early steroid therapy in IgA nephropathy: still an open question (comment). Nephron 1989:51:289-91, Comment on: Nephron $1988: 48: 12-7$.

- Article commented on Kobayashi Y. Fujii K. Hiki Y, Tateno S, Kurokawa A, Kamiyama M. Steroid therapy in IgA nephropathy: a retrospective study in heavy proteinuric cases (see comment). Nephron 1988:48:12-7. Comment in: Nephron 1989:51:289-91.

- Article with published erratum Schofield A. The CAGE questionnaire and psychological health (published erratum appears in $\mathrm{Br} J$ Addict 1489:84:701). Br J Addict 1988:83:761-4.

Books and other monographs

- Personal author(s) Colson JH, Armour WJ. Sports injuries and their treatment. 2nd rev, ed. London: S. Paul, 1986.

- Editor(s) or compiler(s) as author(s) Diener HC, Wilkinson M, editors. Drug-induced headache. New York: Springer-Verlag, 1988.

- Organization as author and publisher Virginia Law Foundation. The medical and legal implications of AIDS. Charlottesville: The Foundation. 1987.

- Chapter in a book Weinstein L. Swartz MN. Pathogenic properties of invading microorganisms. In: Sodeman WA Jr, Sodeman WA, editors. Pathologic physiology: mechanisms of disease. Philadelphia: Saunders, 1974:457-72.

- Conference proceedings Vivian VL, editor. Child abuse and neglect: a medical community response. Proceedings of the First AMA National Conference on Child Abuse and Neglect; 1984 Mar 30-31; Chicago. Chicago: American Medical Association, 1985.

- Conference paper Harley NH. Comparing radon daughter dosimetric and risk models. In: Gammage RB, Kaye SV, editors. Indoor air and human health. Proceedings of the Seventh Life Sclences Symposium: 1984 Oct 29-31: Knoxville (TN). Chelsea (MI): Lewis, 1985:69-78.

- Scientific or technical report Akutsu T. Total heart replacement device. Bethesda (MD): National Institutes of Health, National Heart and Lung Institute; 1974 Apr. Report No.: NIH-NHLI-69-2185-4.
- Dissertation

Youssef NM. School adjustment of children with congenital heart disease (dissertation). Pittsburgh (PA): Univ. of Pittsburgh, 1988

- Patent

Harred JF, Knight AR, Mcintyre JS, inventors. Dow Chemical Company, assignee. Epoxidation process. US patent 3,654,317, 1972 Apr 4.

Other published material

- Newspaper article Rensberger B, Specier B: CFCs may be destroyed by natural process. The Washington Post 1989 Aug 7: Sect A:2(col 5).

- Audiovisual AIDS epidemic: the physician's role (videorecording). Cleveland $(\mathrm{OH})$ : Academy of Medicine of Cleveland, 1987.

- Computer file Renal system (computer program). MS-DOS version. Edwardsville (KS): Medi-Sim, 1988.

- Legal material Toxic Substances Control Act Hearing on S, 776 Before the Subcomm, on the Environment of the Senate Comm. on Commerce, 94th Cong., Ist Sess. 343 (1975).

- Map Scotland (topographic map). Washington: National Geographic Society (US), 1981.

- Book of the Bible Ruth 3:1-18. The Holy Bible. Authorized King James version. New York: Oxford Univ. Press, 1972.

- Dictionary and similar references Ectasia. Dorland's illustrated medical dictionary. 27th ed. Philadelphia: Saunders, 1988:527.

- Classical material The Winter's Tale: act 5, scene 1, lines 13-16. The complete works of William Shakespeare, London: Rex, 1973.

\section{Unpublished material}

- In press

Lillywhite HB, Donald JA. Pulmonary blood flow regulation in an aquatic snake. Science. In press.

\section{Tables}

Type each table double spaced on a separate sheet. Do not submit tables as photographs. Number tables consecutively in the order of their first citation in the text and supply a brief title for each. Give each column a short or abbreviated heading. Place explanatory matter in footnotes, not in the heading. Explain in footnotes all nonstandard abbreviations that are used in each table. For footnotes use the following symbols, in this sequence: $*, \dagger, \ddagger, \S, \mathbb{T}, * *, \dagger \dagger$ etc.

Identify statistical measures of variation such as standard deviation and standard error of the mean.

Do not use internal horizontal or vertical rules.

Be sure that each table is cited in the text.

If you use data from another published or unpublished source, obtain permission and acknowledge fully.

The use of too many tables in relation to the length of the text may produce difficulties in the layout of pages. Examine issues of the journal to which you plan to submit your paper to estimate how many tables can be used per 1000 words of text. 
The editor, on accepting a paper, may recommend that additional tables containing important backup data too extensive to publish be deposited with an archival service, such as the National Auxiliary Publication Service in the United States, or be made available by the authors. In that event an appropriate statement will be added to the text. Submit such tables for consideration with the paper.

\section{Illustrations}

Submit the required number of complete sets of illustrations, or "figures." Figures should be professionally drawn and photographed; freehand or typewritten lettering is unacceptable. Instead of original drawings, roentgenograms and other material send sharp, glossy black and white photographic prints, usually $127 \times 173 \mathrm{~mm}(5 \times 7 \mathrm{in})$ but no larger than 203 $\times 254 \mathrm{~mm}(8 \times 10 \mathrm{in})$. Letters, numbers and symbols should be clear and even throughout and of sufficient size that when reduced for publication will still be legible. Titles and detailed explanations belong in the legends, not on the illustrations themselves.

Each figure should have a label pasted on its back indicating its number, the first author's name and the top of the figure. Do not write on the back of the figures or scratch or mark them using paper clips. Do not bend them or mount them on cardboard.

Photomicrographs must have internal scale markers. Symbols, arrows or letters used in the photomicrographs should contrast with the background.

If photographs of persons are used, either the subjects must not be ifientifiable or their pictures must be accompanied by written permission to use the photographs.

Figures should be numbered consecutively in the order of their first citation in the text. If a figure has been published acknowledge the original source and submit written permission from the copyright holder to reproduce the material. Permission is required irrespective of authorship or publisher, except for documents in the public domain.

For illustrations in colour ascertain whether the journal requires colour negatives, positive transparencies or colour prints. Accompanying drawings marked to indicate the region to be reproduced may be useful to the editor. Some journals publish illustrations in colour only if the author pays for the extra cost.

\section{Legends for illustrations}

Type legends for illustrations double spaced, starting on a separate page, with arabic numerals corresponding to the illustrations. When symbols, arrows, numbers or letters are used to identify parts of an illustration, identify and explain each one clearly in the legend. Explain the internal scale and identify the method of staining in photomicrographs.

\section{UNITS OF MEASUREMENT}

Measurements of length, height, weight and volume should be reported in metric units (metre, kilogram, litre, etc) or their decimal multiples.

Temperatures should be given in degrees Celsius. Blood pressures should be given in millimetres of mercury.
Hematologic and clinical chemistry measurements shoul be reported in the metric system in terms of the Internationa System of Units (SI). Editors may request that alternative o non-SI units be added by the author before publication.

\section{ABBREVIATIONS AND SYMBOLS}

Use only standard abbreviations. Avoid abbreviations it the title and in the abstract. The full term for which at abbreviation stands should precede its first use in the tex unless it is a standard unit of measurement.

\section{SUBMISSION OF A MANUSCRIPT}

Mail the required number of manuscript copies in a heavy paper envelope, enclosing the manuscript copies and illustra tions in cardboard, if necessary, to prevent bending photographs during mail handling. Place photographs an transparencies in a separate heavy-paper envelope.

Manuscripts must be accompanied by a covering letter signed by all co-authors. This must include the following: (a information on prior or duplicate publication or submission elsewhere of any part of the work, as defined earlier in thi document; (b) a statement of financial or other relationship that might lead to a conflict of interest; (c) a statement that the manuscript has been read and approved by all the authors that the requirements for authorship as previously stated in this document have been met and, furthermore, that each co-author believes that the manuscript represents honest work; and (d) the name, address and telephone number of thi corresponding author, who is responsible for communicating with the other authors about revisions and final approval of the proofs. The letter should give any additional information that might be helpful to the editor, such as the type of article in the particular journal that the manuscript represents and whether the author(s) will be willing to meet the cost of reproducing colour illustrations.

The manuscript must be accompanied by copies of any permissions to reproduce published material, to use illustrations of or report sensitive personal information about identifiable persons or to acknowledge persons for their contributions.

\section{PARTICIPATING JOURNALS}

Journals that have notified the International Committee of Medical Journal Editors of their willingness to consider for publication manuscripts prepared in accordance with earlier versions of this document identify themselves as such in their information for authors. A full list is available on request from the New England Journal of Medicine or the British Medical Journal. Citations of this document should be to one of the following sources.

International Committee of Medical Journal Editors. Uniform requirements for manuscripts submitted to biomedical journals. N Engl J Med 1991;324:424-8.

International Committee of Medical Journal Editors. Uniform requirements for manuscripts submitted to biomedical journals. BMJ 1991;302:338-341. 


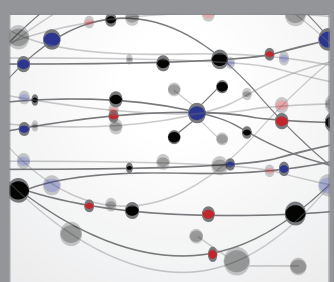

The Scientific World Journal
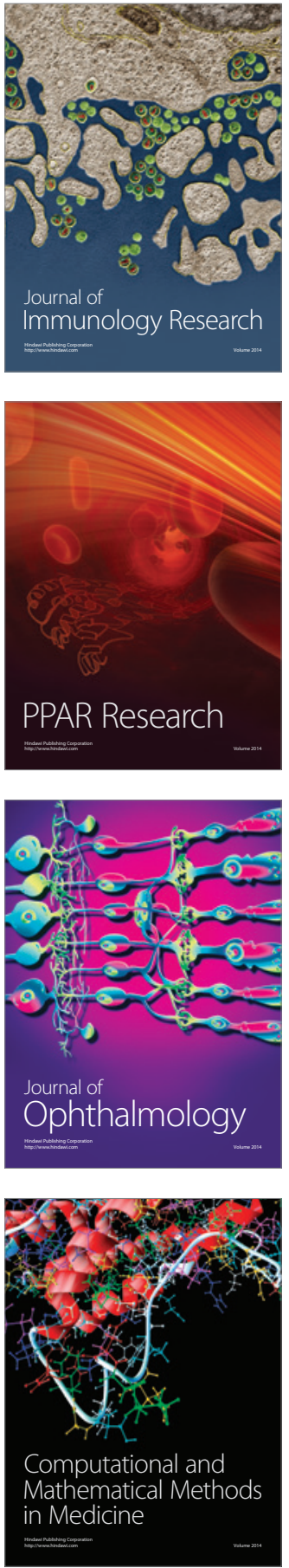

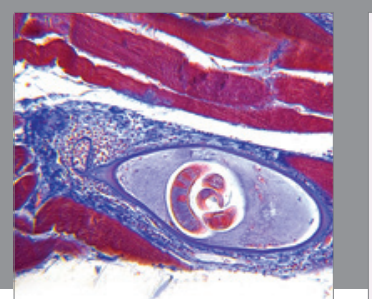

Gastroenterology Research and Practice

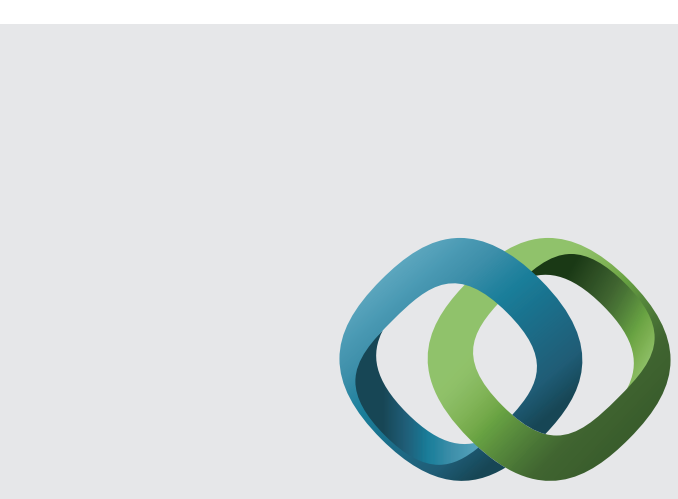

\section{Hindawi}

Submit your manuscripts at

http://www.hindawi.com
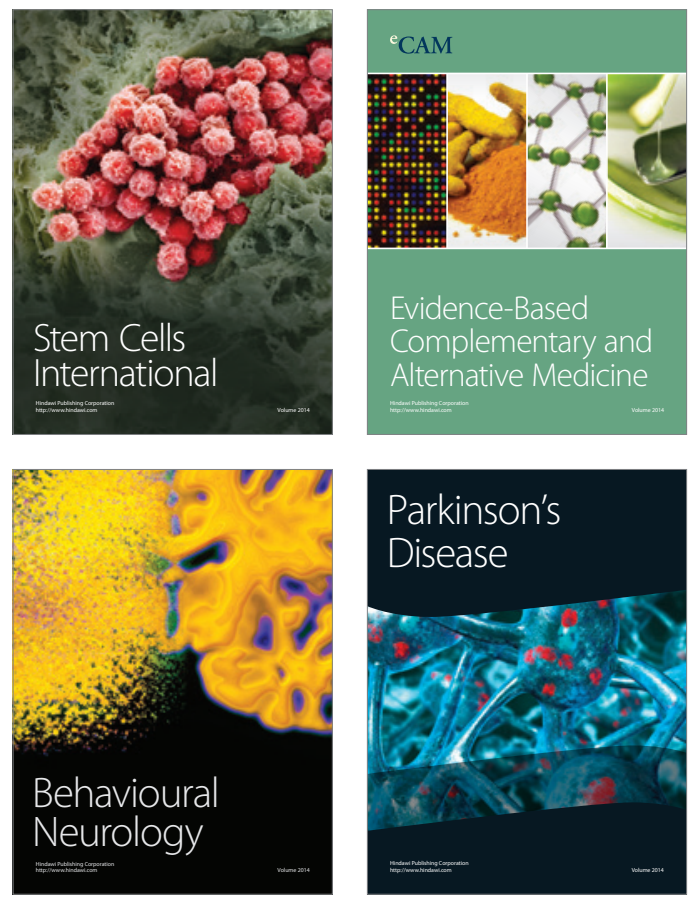
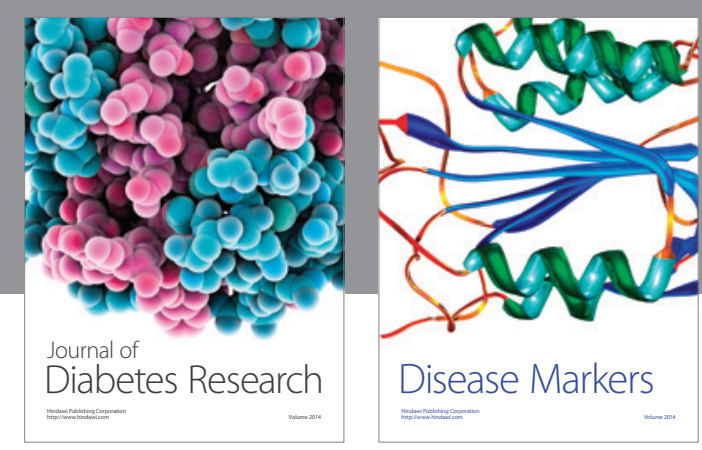

Disease Markers
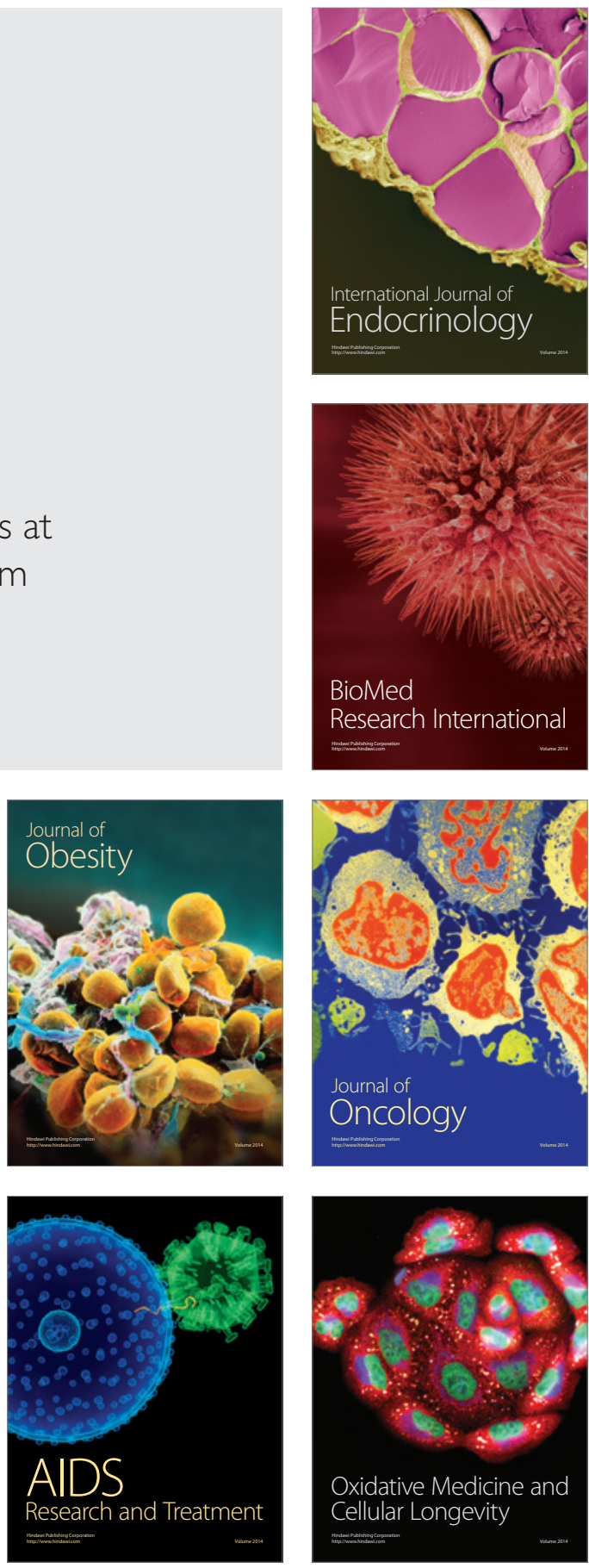